\title{
Automação e agência humana na Linha 4-Amarela do metrô de São Paulo ${ }^{1}$
}

Janice Caiafa

Resumo: Consideramos o metrô como um conjunto de circuitos comunicacionais em que circulam mensagens e pessoas. Os circuitos comunicacionais de um metrô compõem uma superfície de interfaces onde se conjugam constantemente o trabalho da máquina e a agência humana. Examinamos neste trabalho alguns aspectos da experiência de automação integral da condução na Linha 4-Amarela do metrô de São Paulo. Com a introdução dos novos automatismos, a presença humana é deslocada e redistribuída, e, ainda, no caso do piloto humano, suprimida, ensejando um novo regime de interfaces. Com base nos dados etnográficos, analisamos a recepção social dessas transformações e exploramos as imbricações entre o técnico e o humano na efetivação desse projeto no contexto das viagens de metrô.

Palavras-chave: processos comunicativos; inovação tecnológica; automação; metrô (São Paulo); etnografia.

Abstract: Automation and human agency in the line 4 of São Paulo subway - We consider the subway as a large ensemble of communicative circuits in which messages and people circulate. A subway's communicative circuits form a surface of interfaces in which machinery work and human agency are coupled. In this paper we investigate aspects of the experience of full automatic train operation in the Yellow Line 4 (Linha 4-Amarela) of the subway in São Paulo. With the introduction of the new automatisms, human presence is displaced and relocated - or suppressed as in the case of the human pilot — creating a new regime of interfaces. Based on ethnographic data, we analyse the social reception of these changes and explore the particular forms of connection between the technical and the human as this project is deployed in the concrete setting of subway rides.

Keywords: communicative processes; technological innovation; automation; subway (São Paulo); ethnography.

1 Este texto foi produzido no âmbito da pesquisa "Reconfiguração dos circuitos comunicacionais na Linha 4 do metrô de São Paulo", que realizo com apoio do CNPq. 


\section{Circuitos comunicacionais}

Em Trilhos da cidade (CAIAFA, 2013), considerei o metrô como um conjunto de circuitos comunicacionais em que circulam mensagens e pessoas. São as mensagens constantemente deflagradas a partir de suportes técnicos e que transitam entre máquinas sob a supervisão humana, ou dirigidas aos passageiros, e ainda aquelas que se estabelecem entre agentes e usuários. Os circuitos comunicacionais de um metrô compõem uma superfície de interfaces onde se conjugam constantemente o trabalho da máquina e a agência humana. A circulação de pessoas se processa ao longo e concomitantemente aos fluxos semióticos no meio sociotécnico do metrô.

Nos metrôs do mundo, cada vez mais as operações são realizadas a distância. De um posto central de comando (CCO - Centro de Comando Operacional), os supervisores trabalham com computadores que recebem informação de todo o sistema (equipamentos fixos e embarcados, câmeras de vigilância) e não cessam de enviar relatórios fazendo circular os dados necessários para a movimentação dos trens, além de supervisionar e controlar os equipamentos elétricos e eletromecânicos no espaço do metrô.

No dia a dia das viagens, os operadores deflagram mensagens visuais e sonoras dirigidas aos usuários. São os avisos sonoros difundidos nas composições ou nas plataformas, por exemplo, e ainda a sinalização que orienta os usuários para o deslocamento no espaço do metrô ao mesmo tempo informando e controlando os fluxos humanos.

Por sua vez, os passageiros estabelecem constantemente interfaces com as máquinas para poder viajar - na compra do bilhete, por vezes, na passagem pelos torniquetes, na utilização dos intercomunicadores. Outras interfaces se estabelecem entre usuários e agentes no quotidiano imprevisível das viagens.

Morley (2011) propõe que se chame "comunicação" tanto a circulação de mensagens quanto a de pessoas e objetos, viabilizando que se explore as "mobilidades diferenciais" que decorrem das diversas regulações impostas a esses fluxos em contextos concretos. Essa expansão do conceito de comunicação é, creio, particularmente interessante para o estudo dos metrôs. Um metrô funciona a partir do estabelecimento de interfaces múltiplas, muitas vezes híbridas de humano e máquina, ao longo de fluxos semióticos e materiais.

Lemos (2009a, p. 28) define o movimento de pessoas, commodities e objetos como uma dimensão da mobilidade junto à dimensão informacional. Para o autor, esses dois aspectos da mobilidade são indissociáveis e produzem impactos um sobre o outro. "Comunicar é deslocar", escreve. Nas "mídias locativas", que Lemos (2009b, p. 91) estuda - dispositivos informacionais ligados ao espaço construído, mídias "'atentas' a lugares e contextos" —, encontramos, a meu ver, um aspecto dessa indissociabilidade.

Na condução dos trens, e ao longo da evolução de suas tecnologias, o humano e o maquínico se imbricam em diversas articulações. A modalidade de condução denominada Condução Manual Livre, em que o piloto conduz o trem auxiliado pela sinalização 
de via, em muitos metrôs é usada apenas em certos períodos do dia, em situações de emergência ou no pátio de manobras. Na modalidade Condução Manual Controlada, o piloto dirige e, num evento como, por exemplo, ultrapassagem de velocidade, o trem freia automaticamente. Na modalidade Piloto Automático - a mais comum nos metrôs hoje -, a máquina conduz o trem e o piloto humano se encarrega de abrir e fechar as portas, além de assumir o controle no caso de falha. Em alguns casos, ele também dá a partida, colocando o trem em movimento.

A automação integral da condução dos trens, embora ainda seja rara nos metrôs pesados (de grande gabarito e alta demanda), parece anunciar-se como o futuro das novas linhas de metrô. Realiza-se em duas modalidades. Na modalidade denominada Driverless Train Operation (DTO), mantém-se um agente no trem para agir em situação de falha da máquina ou de incidentes em geral durante as viagens. Na modalidade Unattended Train Operation (UTO), condução "desatendida", o equipamento embarcado conduz o trem - auxiliado por equipamentos fixos nas estações e sob a supervisão do CCO - sem nenhum humano a bordo (SOUZA, 2008).

À frente de nossa composição pode estar apenas uma inteligência artificial. A evolução das tecnologias de comunicação e informação foi introduzindo automatismos e implantando meios de controle a distância em diversos níveis da operação do metrô - ao implantar sistemas de ajuda à condução (nas modalidades Condução Manual Controlada e Piloto Automático) ou mesmo suprimir o condutor humano, ao criar as salas de controle (CCO) e ao gerar múltiplas interfaces técnicas de envio e recepção de mensagens entre equipamentos. Há uma espécie de desmaterialização no ambiente do metrô.

Ao mesmo tempo, o metrô permanece um meio de transporte que conduz pessoas, com todas as vicissitudes e acidentes que o choque de materialidades envolve. Os artefatos técnicos também participam dessa dinâmica, em relação com os humanos e à mercê de seus repertórios variados e imprevisíveis no quotidiano do metrô. A desmaterialização de um ambiente em que o componente tecnológico tem forte presença e o imperativo material que o próprio objetivo do metrô implica (transportar pessoas) convergem, criando uma dinâmica particular.

Tentarei em seguida explorar aspectos dessas convergência no quotidiano de uma linha totalmente automatizada, a Linha 4-Amarela do metrô de São Paulo. São indicações construídas através de uma pesquisa etnográfica, em que recorro à minha observação participante como usuária e a conversas com diversos interlocutores $-^{2}$ membros dos quadros diretores da concessionária que opera a linha, a ViaQuatro, e da Companhia do Metropolitano de São Paulo, ${ }^{3}$ que opera as outras linhas do sistema, e ainda condutores,

2 Agradeço especialmente a Caetano Jannini, Jorge Secall e Peter Alouche. Sou muito grata também a Manuel Xavier Lemos Filho, Adão de Oliveira Leite, Almir de Castro, Mauricio Dimitrov, Serge Soler, Corinne Schwebel, Roque Lázaro Rosa, Wilson Garcia Martins, Conrado Grava de Souza, Cristina Freitas, Rogerio Belda, Lucas Oliveira, José Roberto Valente e Vladimir Freire.

3 Doravante nomeada "Metrô de São Paulo" ou "Metrô". 
agentes de estação e usuários. Após algumas observações sobre a Linha 4 e o metrô de São Paulo, o leitor verá aparecer algumas dessas vozes, ao lado da minha.

\section{Linha 4-Amarela: várias inovações}

A Linha 4-Amarela, inaugurada em maio de 2010, ocupa uma posição singular no sistema metroviário de São Paulo. ${ }^{4}$ Em primeiro lugar, trata-se de uma linha integradora. Seu traçado, ao cruzar a Linha 2-Verde, a Linha 3-Vermelha e ainda a Linha 9-Esmeralda da ferrovia em pontos cruciais da rede, estabeleceu novas transferências que permitem atender muito mais eficientemente a demanda. Interlocutores meus, profissionais do Metrô de São Paulo e da ViaQuatro, observaram esse ponto. Muitos usuários com quem conversei afirmaram que com a Linha 4 seu tempo de viagem se reduzira expressivamente.

A Linha 4-Amarela reúne, além disso, várias inovações em nível de tecnologia e de gestão. A grande inovação tecnológica consiste, sem dúvida, no modo de condução dos trens, que dispensa o condutor humano. Trata-se da primeira linha metroviária totalmente automatizada da América Latina. Foi preparada para operar na modalidade unattended ou unmanned.

Outras inovações tecnológicas podem acompanhar a implementação do modo de condução totalmente automática num metrô, e não tem sido diferente no caso da Linha 4. Como mais operações se tornam remotas, novos dispositivos costumam povoar trens e estações. Há mais investimento na segurança - e, portanto, na vigilância - e os trens são equipados com câmeras de vídeo e dispositivos para comunicação sonora com o CCO. A ausência do condutor humano, e mesmo a redução do número de agentes (objetivo em geral buscado no contexto da introdução de um sistema integrado de automatismos), associam-se a um maior investimento nos dispositivos técnicos e à utilização de tecnologia de ponta no material rodante e nas estações.

A instalação de portas de plataforma é comum nas linhas automáticas e visa solucionar o problema de segurança colocado pela ausência do piloto humano. Essas portas, que se movimentam em sincronia com as do trem, formam uma fachada na plataforma e fecham a via, impedindo assim a queda de objetos e de pessoas. No caso da Linha 4-Amarela, além das portas de plataforma, foram instaladas em algumas estações portas automáticas no nível das linhas de bloqueio (torniquetes). Esses automatismos não são introduzidos apenas em linhas automáticas, mas a Linha 4-Amarela concentrou uma série de experimentos. Outro exemplo é a implementação de uma tecnologia de ponta para a comunicação entre a via, o trem e o CCO, o CBTC (Communication Based Train Control), que opera através de ondas de rádio. O sistema CBTC já começou a ser instalado em outras linhas do metrô de São Paulo.

4 O sistema metroviário de São Paulo compreende atualmente 5 linhas: Linha 1-Azul, Linha 2-Verde, Linha 3-Vermelha, Linha 4-Amarela e Linha 5-Lilás. Com seis estações já construídas e em operação comercial Butantã, Pinheiros, Faria Lima, Paulista, República e Luz -, a Linha 4-Amarela transporta uma média de 650 mil passageiros num dia útil. Disponível em: <http://www.viaquatro.com.br>. Acesso: 28 de junho de 2014 
Quanto ao material rodante, cada trem da Linha 4 tem 26 câmeras que enviam imagens de dentro e mais duas, uma em cada cabeceira, voltadas para a via. Não há divisórias entre os vagões, as composições se estendem num salão contínuo, o que se denomina "trem tubo". 5

A gestão de pessoal também foi inovada na Linha 4 - em relação à organização que vigora nas outras linhas do metrô de São Paulo e em geral num metrô -, e as tarefas principais que o trabalho do metroviário envolve, operação, manutenção e segurança, sofreram um rearranjo. Ocorreu um processo de convergência das funções do agente, resultando em uma polivalência. Os agentes podem, por exemplo, ocupar-se do atendimento ao usuário e fazer trabalho de manutenção.

Essa característica da gestão humana, a polivalência das funções, decorre, em parte, das novas exigências impostas pelo complexo sistema integrado de automatismos. Ao mesmo tempo, coloca-se a serviço da redução de pessoal, imperativo que está presente igualmente na situação de supressão do condutor, e é um aspecto da preocupação com a produtividade. Em conexão com esse ponto, note-se que a operação da nova linha, diferentemente das outras, foi concedida à iniciativa privada no âmbito de uma PPP (Pareceria Público Privada). ${ }^{6}$

Um interlocutor pertencente aos quadros superiores da operadora ViaQuatro utilizou, em nossa conversa, o termo "otimização" para descrever esse processo de reorganização do trabalho do agente. A inovação tecnológica ocorre acompanhada de uma reforma organizacional.

Com o rearranjo, a redução ou o desaparecimento da presença humana (no caso do condutor) e o investimento em novos e sofisticados dispositivos técnicos, ocorre, na Linha 4-Amarela, uma configuração particular dos circuitos comunicacionais. Num metrô, a operação depende da produção de interfaces dos agentes entre si e com as máquinas, das interfaces que se estabelecem entre os dispositivos técnicos e daquelas que se oferecem aos usuários. Estes, para poder viajar, ingressam nesses circuitos híbridos. No contexto da automação integral da condução, com a presença mais expressiva da máquina e o rearranjo da presença humana, as interfaces, ao longo desses circuitos, tendem a se organizar sob um novo regime.

Por outro lado, a difusão e a recepção de uma tecnologia - e da reorganização da presença humana que a acompanha - admitem apropriações e resistências, e podem

5 Entrevista com Jorge Martins Secall, na época, diretor de Operações e Manutenção da ViaQuatro. Em: Sistema driverless. Revista Ferrovia, abril de 2010.

6 As Parcerias Público-Privadas (PPP) são contratos de concessão em que o parceiro privado, além de realizar a operação, faz investimentos em infraestrutura. Esses são amortizados e remunerados pelo aporte de verbas públicas a partir do início efetivo da prestação do serviço. Com a Linha 4-Amarela foi assinado o primeiro contrato PPP do Brasil, em 26 de novembro de 2006. O consórcio ganhador da licitação é formado pelo Grupo Camargo Corrêa (através da CCR, que atua no segmento de transporte), Montgomery Participações S.A., Mitsui \& Co., RATP Développement e Benito Roggio Transporte S.A. O consórcio opera a linha sob o nome de ViaQuatro. Cf. Toledo (2013), Manual de Parcerias Público Privadas - PPPs - e no site: <http://www.viaquatro. com.br/a-via-quatro/estrutura-acionaria>. Acesso: 28 de junho de 2014. 
se dar por rumos que as contingências acabam impondo. No caso da Linha 4-Amarela, é interessante observar as imbricações entre o técnico e o humano na efetivação desse grande projeto em nível das práticas sociais concretas do quotidiano do metrô.

\section{Viajando na Linha 4-Amarela}

No trem tubo, o olhar pode percorrer grande distância através dos vagões e sem barreiras. Não há condutor humano e estão vagas as duas cabines, uma em cada ponta da composição. De lá, através de uma ampla janela, pode-se observar o trilho, regular e limpo, que corre sob o trem durante a breve viagem. Por vezes, um outro trem passa na direção oposta.

Conversando com um agente, perguntei se as pessoas em geral procuram se informar sobre a questão da ausência do condutor ou se parecem preocupadas. Ele me disse que perguntavam apenas no começo, logo que abriram a linha. Uma agente, com quem conversei na plataforma da estação Paulista, disse-me que às vezes perguntam, mas não com medo, só querendo saber. "É seguro?" - disse ela, citando um usuário.

Até agora, em minhas conversas com usuários, ninguém declarou se preocupar muito com essa questão. Alguns disseram que pensavam no início sobre isso e depois se acostumaram. De fato, como com outras tecnologias, tendemos a nos adaptar e automatizamos, nós mesmos, a nossa relação com elas. Mas alguns usuários trazem a questão de possíveis acidentes. Rafael observou:

Eu acho assim, numa pane, por exemplo, devido à profundidade dessa estação, aqui é tudo ar condicionado. Se caso falte isso eu acho que vai ter um certo pânico aqui. O pessoal pra ser retirado daqui, só com cordas.

Em conversa durante uma viagem na linha, comentou Marco: "É indiferente. Se acontecer alguma coisa, com piloto ou sem piloto ia acontecer".

- Você sabe que esse trem não tem piloto? - perguntei a uma usuária.

- Sabia.

- E como você se sente?

- Ah, eu nem paro pra pensar muito nisso. Porque não tem muito acidente, não tenho medo dele. Eu fui lá no primeiro vagão, vi como é, mas prefiro não pensar muito.

Um outro assunto que abordei nas conversas se refere a uma descoberta que fiz logo no início da pesquisa. Constatei que havia um agente que viajava no trem - embora a condução na Linha 4-Amarela fosse supostamente unattended.

Na minha primeira viagem, tive notícia da sua presença. Foi uma agente com quem conversei que o mencionou. Estava com sorte porque naquela mesma ocasião consegui avistá-lo, assim como em muitas outras a seguir. Em conversas com usuários, ouvi algumas 
histórias a seu respeito, embora nem todos o tivessem visto no trem ou soubessem por que estaria ali.

É um agente de manutenção, disse-me essa agente que primeiro me informou a respeito, um AM. Depois, conversando com um dos diretores da concessionária, aprenderia que se trata de um AAM1 - Agente de Atendimento e Manutenção 1. A agente me contou que quando as luzes se apagam no trem - o que pode durar alguns segundos - ele trata de tranquilizar as pessoas. Um dos diretores me diria, em seguida, que esse problema técnico já teria sido sanado.

- Elas ficam assustadas? - perguntei.

- Assustadas, não, mas eu vejo as carinhas de espanto.

\section{Homem a bordo}

A questão do agente no trem se tornaria importante para a pesquisa. Passei a levantar este ponto nas conversas com os profissionais envolvidos de diversas maneiras com a Linha 4. Diante desse fato, em geral não mencionado espontaneamente, há interpretações diferentes.

O agente a bordo não figurava no projeto da linha. Como já indiquei, o modo de condução eleito e construído foi o UTO (Unattended Train Operation), sem agente a bordo - e não o DTO (Driverless Train Operation), condução automática com agente.

Estava previsto, inclusive, que a presença humana seria escassa em todo o espaço das estações. Agentes itinerantes percorreriam o sistema e o usuário pediria auxílio, sobretudo, através de intercomunicadores. As estações resultariam praticamente vazias e no trem não haveria nenhum tipo de atenção humana. Aliás, esse é o modelo adotado nas linhas 1 e 14 do metrô de Paris, ambas automáticas, que inspiraram o projeto da Linha 4-Amarela.

Um engenheiro do Metrô de São Paulo, envolvido com a implementação da Linha 4-Amarela, contou-me que a "operação branca" da linha, ou seja, os testes antes da abertura para operação comercial, foi muito acidentada. Nessa fase da operação, testa-se, por exemplo, se o trem estaciona na posição correta na estação. "O trem parava antes, ou depois, ou nem parava". Demorou muito para corrigir, contou-me. O Metrô então passou a exigir da concessionária que o quadro de segurança na estação fosse reforçado. O monitoramento teria que ser presencial. Segundo entendi em conversa com ele e com outros, e como eu mesma constatei, hoje há agentes nas estações ainda em maior número do que o exigido naquele momento inicial pelo Metrô.

E o homem a bordo? Sua origem estaria aqui, no contexto da constatação da necessidade da presença humana diante das falhas da máquina.

Por outro lado, não é essa a explicação dos representantes da concessionária. Um profissional com quem conversei me disse que a presença do atendente no trem se deve ao fato de que certos dispositivos técnicos não foram instalados ainda nos trens. 
Por exemplo, falta um sistema de sonorização que permita uma comunicação bidirecional entre usuário e CCO. Sem esse dispositivo não seria possível garantir a modalidade desatendida.

Um outro profissional que trabalhou na implementação da Linha 4-Amarela me relatou que o motivo para colocar um agente no trem foi o problema da interface das portas do trem e da plataforma. Elas devem abrir e fechar em sincronia. Um desacordo entre elas compromete o embarque e o desembarque de passageiros, podendo ocasionar interrupções do tráfego de trens e, certamente, expor os passageiros a mais riscos que os que já há nesse patamar tão sensível. Um problema na interface técnica das portas pode causar uma falha na parada do trem automático - que pode se posicionar aquém ou além, ou ainda não parar na estação -, como aconteceu na operação branca.

Um engenheiro do Metrô de São Paulo já havia mencionado em nossa conversa esse desencaixe na interface técnica das portas como um dos problemas iniciais na operação da linha. Ele assinalou que, na época, uma das dificuldades para encontrar uma solução vinha de que se tratava de diferentes fornecedores e nenhum queria se responsabilizar. No contrato de concessão, as portas de plataforma foram providenciadas pelo Estado, enquanto a concessionária comprou o material rodante.

Quem justamente costuma velar pelo bom funcionamento dessas interfaces no dia a dia do metrô? Como já vimos, é o condutor que se encarrega da abertura e do fechamento das portas e intervém numa emergência. Mas numa linha automática ele não está.

O homem a bordo, que ninguém quer comentar - quase um agente secreto -, teria sido chamado em socorro dos imprevisíveis a cargo do condutor e que podem se dar também por intervenção humana. Há ocasiões, por exemplo, em que os próprios usuários impedem o fechamento das portas para poder embarcar. Roberto, condutor com quem conversei, acha que as portas de plataforma são ineficazes como dispositivo de segurança: "É mais uma porta para o usuário segurar", observou.

Em conexão com esse ponto, há a questão mais geral da pertinência ou não da implementação da automação integral da condução em metrôs pesados. Verifiquei que essa questão existe nos meios técnicos ligados ao metrô de São Paulo. Há quem acredite que, num metrô pesado e especialmente carregado como o metrô de São Paulo, os riscos do imprevisível tornam imprescindível a presença do condutor humano.

Alouche (1991, p. 11) escreve que o nível de demanda de um sistema de transporte "pode determinar não somente o grau de automação mas, principalmente, o seu conceito e definição". O autor afirma mais adiante, após descrever as qualidades da automação integral e a confiabilidade que proporciona em relação às ações humanas:

A automação não pode e não deve ser um fim em si. Embora seu campo de aplicação seja dos mais vastos, ela deve responder sempre a uma necessidade emergente. Essa necessidade é a qualidade de serviço cujo padrão é a própria sociedade que impõe. (lbid., p. 17) 
Numa linha em que a condução é totalmente automatizada, as funções remotas são enfatizadas e o CCO assume um papel mais fundamental. Foi assim que as características da operação da Linha 4 me foram descritas - uma operação verticalizada, "matricial", em que a matriz, o controle do CCO, deveria preponderar sobre o trabalho dos agentes locais. Fui percebendo, contudo, que se tratava muito mais de um projeto, de um desenho ideal, e que de fato não era isso o que concretamente se passava. Ao visitar as estações, encontrava vários agentes. E, ainda, ao conversar com eles, entendi que a comunicação, por enquanto, permanecia horizontal, ou em grande parte. Uma outra configuração parecia se impor na prática.

Na presença do agente nos trens, observamos igualmente o recurso à agência humana num sistema previsto para delegar o máximo à máquina. Numa linha de condução automática unattended, o agente a bordo é, sem dúvida, a figura mais proeminente dessa persistência do humano e da tensão entre o previsto e o realizado na Linha 4-Amarela.

Quem é esse agente, esse itinerante solitário num trem que segue por si mesmo? E o que ele faz de fato ou, ainda, o que poderia fazer no caso de uma emergência?

Daniel, usuário frequente do metrô, conta que já foi interpelado por ele.

- Você já viu esse agente em contato com alguém, falando com alguém? perguntei.

- Eu vi. Já fui abordado algumas vezes por conta do pé apoiado na lateral do banco. Já vi e já fui abordado também.

- O que ele disse pra você?

- Quando eu vi ele chegando eu percebi que não podia. Eu tirei o pé, virei o pé pra baixo. Aí ele fez um "joia" pra mim. Não chegou a falar nada porque eu percebi que ele vinha.

- Alguma outra ocasião?

- Que eu fui abordado não. Eu já vi outras pessoas sendo abordadas e ele falando:

"Ah, tira o pé do banco!".

Quando há uma pane, quem vai retirar o trem da via?É o agente do trem, o AAM1? Foi o que perguntei a um profissional com quem conversava. Exatamente, ele mesmo. Ele pode conduzir o trem e entende de manutenção do material rodante. O AAM2, que fica na estação e não no trem, sabe muito mais de manutenção. É ele que, quando não está atendendo, faz a manutenção corretiva e preventiva dos equipamentos. O agente a bordo pode socorrer o usuário se ele passar mal? Segundo entendi, ele não entende de primeiros socorros e tem que chamar outro agente nessa eventualidade.

Outros usuários mencionaram circunstâncias semelhantes em que o agente se dirigiu a passageiros para uma espécie de correção de conduta. O caso dos pés no banco é emblemático. De fato, a ação do homem de bordo não pode ser de ordem operacional frequentemente - no caso de pane, por exemplo - posto que, se fosse assim, a operação seria muito acidentada e se inviabilizaria. E o quanto ele poderá socorrer nessas ocasiões? 
A resposta não é clara, a questão é objeto de controvérsia. Um interlocutor meu do Metrô de São Paulo, discordando do profissional da concessionária, observou que sua habilidade para conduzir o trem não está garantida, já que o agente não poderia ter prática de condução, tendo inclusive que assumir o controle em situações de grande tensão.

A observação mostra que uma característica muito presente do trabalho desse agente secreto é a tarefa policial de controle de conduta. Esse trabalho constante de fiscalização certamente não cabe ao condutor, já que ele antes de tudo se coloca ao lado da máquina para conduzir o trem, só interferindo nas viagens em momentos excepcionais. Para os passageiros, na situação do trem automático com agente a bordo, o resultado é um ambiente mais vigiado. O agente no trem se torna uma extensão das câmeras.

É certo que se espera dele também, claro, que vigie as posturas da máquina, e não só as dos passageiros. E, ao que relataram alguns profissionais, parece estar ali, sobretudo, para velar pelo embarque e desembarque, já que as portas, por sua vez, não tiveram um bom desempenho. $\mathrm{O}$ interlocutor que apontou o problema das portas como a razão do agente a bordo acrescentou que talvez isto tenha sido resolvido, mas, disse ele, "quando se coloca alguém ali fica difícil tirar".

\section{Vicissitudes da delegação}

Bjker e Law (1992, p. 11) escrevem que a tecnologia não surge como "fonte desinteressada de inovação". A inovação não é impulsionada por uma lógica técnica que determinaria uma trajetória obrigatória. Emerge, ao contrário, de processos conflituosos e condicionada por imperativos sociais, políticos, econômicos e técnicos no contexto de estruturas existentes. O arranjo que se nos apresenta finalmente, contudo, pode parecer o único possível e a sua acolhida o caminho a seguir.

Como mostra Akrich (1992), os processos envolvidos na própria construção dos objetos técnicos tendem a ser ocultados. Há um fenômeno de naturalização, diz a autora, dos vínculos causais estabelecidos. A análise, portanto, deveria considerar essa naturalização ao examinar as novas forças que emergem no contexto da difusão social de uma tecnologia e que trazem mais diferença e conflito.

Um dispositivo forte de ocultamento da complexidade desses processos é o critério da eficiência erigido como modelo. Hess (2007, p. 71) mostra como, nesse caso, "a tecnologia é vista como um campo autônomo que se desenvolve de acordo com sua própria lógica interna de invenção e eficiência". O processo de difusão e adoção da inovação adquire "a marca do inevitável" (ibid., p. 72). Na mesma linha, Perrin (1996, p. 109) afirma que "é mais confortável pensar que as técnicas se desenvolvem de maneira autônoma e tudo o que se pode esperar é limitar suas consequências nefastas sobre o emprego e o meio-ambiente". 
Na construção de uma tecnologia e no processo de sua difusão e recepção social, descobrimos confrontos e resistências e não um caminho retilíneo determinado pela neutralidade da eficiência. Desde o início os sistemas técnicos estão imbuídos do social e do político. São, desde a sua origem, humanos também. Sua exposição à sociedade mais ampla acirra as forças em jogo. As contingências podem determinar novos desenlaces.

O projeto de automação integral da condução na Linha 4-Amarela envolvia a redução da presença humana nos trens e nas estações. Outras soluções, contudo, impuseram-se e delegou-se aos humanos boa parte do trabalho nas estações. Nos trens um homem foi levado a bordo para fazer companhia à máquina, ao menos por enquanto.

Latour (1992) explora a situação de divisão de trabalho entre humanos e artefatos técnicos ao expressá-la como um processo de "delegação". Haveria uma "distribuição de competências" entre humanos e não-humanos. Essa distinção seria, além disso, pouco importante. Haveria antes que considerar uma "cadeia" e as gradações ao longo dela, na medida em que se a percorre, delegando as tarefas segundo as competências. Para deslocar a ênfase das extremidades e enfatizar as gradações e a delegação de tarefas, o autor prefere, a "atores", a denominação "actantes" - "alguns humanos, alguns não-humanos, alguns competentes, outros incompetentes" (ibid., p. 236).

Na Linha 4-Amarela do metrô de São Paulo, foi preciso, ao que parece, convocar mais humanos para desempenhar tarefas, em contraste com o que havia sido previsto. Um número maior de agentes foi designado para o desempenho do trabalho de estação. $\mathrm{E}$, nas composições preparadas para o modo unattended, colocou-se um agente especial - secreto ao se evitar referir-se a ele, ostensivo em sua atividade de supervisão nas viagens, e provavelmente indispensável, do contrário não estaria ali. A delegação de tarefas que mobiliza o trabalho da máquina e a agência humana é um processo complexo, comportando idas e vindas.

É interessante a explicação, já citada acima, desse meu interlocutor, ao atribuir a presença do homem a bordo a problemas na interface das portas dos trens e das plataformas. Trata-se de um flanco vulnerável em qualquer metrô. Nas linhas não automáticas, é justamente o condutor que tem o papel de guardião dessa interface. O controle a distância pode, em algumas ocasiões, não bastar para garantir a segurança dos passageiros no embarque e no desembarque e a normalidade do tráfego das composições.

A operação dos metrôs se torna cada vez mais desmaterializada, mas seu objetivo maior é deslocar pessoas em relação com objetos tangíveis num quotidiano de imprevisíveis.

Todo projeto, poder-se-ia dizer, enfrenta as contingências de sua concretização. De fato, e em especial no caso do embate entre a aposta no incontornável da inovação tecnológica e a sutileza dos processos humanos - inclusive em companhia das máquinas - no conjunto complexo de interfaces híbridas do ambiente do metrô.

O metrô funciona através de circuitos comunicacionais com suas múltiplas interfaces do humano com o humano, do técnico com o técnico, do técnico com o humano. 
Na Linha 4-Amarela outras interfaces humanas, não previstas, estabeleceram-se no contexto desse sistema integrado de automatismos. A experiência da automação integral da condução e de todas as novidades tão interessantes da Linha 4-Amarela mostram a complexidade da recepção da tecnologia no contexto das relações sociais concretas. A criatividade da ação humana que projetou a tecnologia e daquela que a opera, supervisiona e utiliza, junto com a força dos fluxos maquínicos - ambos com sua confiabilidade e seus fracassos - traçam um quadro muito interessante e dinâmico que vale a pena investigar.

Janice Caiafa é doutora em Antropologia pela Universidade de Cornell (EUA), Professora Associada da Escola de Comunicação da UFRJ, poeta e pesquisadora do CNPq.

janicecaiafa@gmail.com

\section{Referências}

AKRICH, M. The De-Scription of Technical Objects. In: BJKER, W. E.; LAW, J. (Orgs.). Shaping technology/building society: studies in sociotechnical change. Cambridge: MIT Press, 1992.

ALOUCHE, P. A automação e a qualidade de um sistema de transporte urbano. In: BRASILCON 91 - IEEE/Qualidade e Produtividade do Setor Elétrico. São Paulo. "Anais..." São Paulo 17 a 19 de setembro de 1991.

BIJKER, W. E.; LAW, J. General introduction. In: BIJKER, W. E.; LAW, J. (Orgs.). Shaping Technology/ building society: studies in sociotechnical change. Cambridge: MIT Press, 1992.

CAIAFA, J. Trilhos da cidade: viajar no metrô do Rio de Janeiro. Rio de Janeiro: 7Letras, 2013.

HESS, D. J. Alternative Pathways in Science and Industry: Activism, Innovation, and the Environment in an Era of Globalization. Cambridge: MIT Press, 2007.

LATOUR, B. Where Are the Missing Masses? The Sociology of a Few Mundane Artifacts. In: BIJKER, W. E.; LAW, J. (Orgs.), Shaping technology/building society: studies in sociotechnical change. Cambridge: MIT Press, 1992.

LEMOS, A. Cultura da Mobilidade. Revista FAMECOS, n. 40, dez. 2009a. Disponível em: <http:// revistaseletronicas.pucrs.br/ojs/index.php/revistafamecos/article/view File/6314/4589>. Acesso em: 15 de junho de 2014.

. Arte e mídia locativa no Brasil. In: ; JOSGRILBERG, F. (Orgs.). Comunicação e mobilidade: aspectos socioculturais das tecnologias móveis de comunicação no Brasil. Salvador: EDUFBA, 2009b.

MANUAL DE PARCERIAS PÚBLICO PRIVADAS - PPPs. Disponível em: <http://download.rj.gov.br/ documentos/10112/167695/DLFE-32801.pdf/manual_PPP.pdf>. Acesso em: 7 jul. 2014.

MORLEY, D. Communications and transport: The mobility of information, people and commodities. Media, Culture \& Society, Vol. 33, no 5, 2011. 
PERRIN, J. Por uma cultura técnica. In: SCHEPS, R. (Org.). O império das técnicas. Campinas: Papirus, 1996.

SISTEMA DRIVERLESS. Linha 4-Amarela, a primeira da América Latina a operar sem a presença de um condutor. Revista Ferrovia, abr. 2010.

SOUZA, C. G. de. Ressinalização do Metrô de São Paulo. In: REUNIÓN INTERMEDIA DE LOS COMITÊS TÉCNICOS DE ALAMYS, 13, Porto Rico. Anais... Porto Rico: 1-6 Junho de 2008.

TOLEDO, L. F. V. de. PPP no Estado de São Paulo: estruturas e impacto no orçamento. Tese (Mestrado em Gestão e Políticas Públicas). Escola de Administração de Empresas de São Paulo da Fundação Getúlio Vargas, 2013. 